GLOSSARY

\title{
Terms in reproductive and perinatal epidemiology: 2. Perinatal terms
}

\author{
Ruby H N Nguyen, Allen J Wilcox
}

J Epidemiol Community Health 2005;59:1019-1021. doi: 10.1136/jech.2004.023465

This is the second of a two part glossary of terms used in reproductive and perinatal epidemiology. The purpose is to provide a reference for terms that are widely (if not always consistently) used in this field. While a glossary cannot resolve all these problems, it provides a point of reference for understanding them. Part 1 covered terms relevant mostly to events and conditions before birth. Part 2 emphasises terms used during the time around and after birth.

See end of article for authors' affiliations

Correspondence to: Dr R H N Nguyen, NIEHS, 111 TW Alexander Drive Epidemiology Branch Mail Drop A3-05 Research Triangle Park, North Carolina 27709, USA; nguyen5@niehs.nih.gov

Accepted for publication 31 August 2004

\begin{abstract}
APGAR SCORE
A widely used tool for assessment of the newborn and the need for resuscitation, based on infant's heart rate, respiratory effort, muscle tone, reflex irritability, and skin colour. The 10 point scale $(0,1$, or 2 for each factor $)$ is applied at one minute and five minutes after birth. While "Apgar" may appear to be an acronym, it was named after its developer, Virginia Apgar. ${ }^{1}$
\end{abstract}

\section{BIRTH INTERVAL}

Elapsed time between a mother's deliveries. This is sometimes calculated as the time from delivery subsequent pregnancy (called "inter-pregnancy interval") to avoid confounding by length of the subsequent pregnancy.

\section{BIRTH WEIGHT}

Weight of the baby (live born or stillborn) at delivery.

\section{Low birth weight (LBW)}

Birth weight less than $2500 \mathrm{~g}$. While LBW is a convenient end point for epidemiological studies, it is subject to criticism for failing to distinguish preterm and small term births. ${ }^{2}$

\section{Very low birth weight (VLBW)}

Birth weight less than $1500 \mathrm{~g}$; almost all VLBW babies are preterm.

\section{FETAL DEATH (STILLBIRTH)}

There is probably no health outcome with a greater number of conflicting, authoritative, legally mandated definitions. The basic WHO definition of fetal death is the intrauterine death of any conceptus at any time during pregnancy. ${ }^{3}$ However, for practical purposes, legal definitions usually require recorded fetal deaths to attain to the last menstrual period (LMP) of the

some gestational age $(16,20,22,24$, or 28 weeks) or birth weight $(350,400,500$, or $1000 \mathrm{~g})$. In the US states, there are eight different definitions by combinations of gestational age and weight, and at least as many in Europe. $^{45}$

\section{Fetal death ratio}

A measure of fetal mortality that compares the number of fetal deaths (stillbirths) with the number of live births over a given period of time.

\section{Fetal mortality rate (stillbirth mortality rate)}

The number of fetal deaths divided by the total number of fetal deaths and live births (expressed per 1000).

\section{FETUS}

The stage of development from about nine weeks after conception until delivery.

\section{GESTATIONAL AGE}

The duration of pregnancy (and thus the age of fetus), measured from the "first day of the last normal menstrual period" or LMP. While it is the most practical basis for dating pregnancy, the LMP in fact occurs two or more weeks before conception. The LMP based gestational age is sometimes adjusted later during pregnancy on the basis of ultrasound examination. ${ }^{6}$ (See OBSTETRIC DATES)

\section{GRAVIDITY}

Number of previous pregnancies (as distinguished from parity, the number of previous births).

\section{Primigravida}

A woman pregnant for the first time.

\section{Multigravida}

A pregnant woman who has been pregnant before.

\section{INFANT MORTALITY}

Death in the first year of life. Widely used as a measure of national social and economic development. (See also NEONATAL MORTALITY; POSTNEONATAL MORTALITY)

\section{Infant mortality rate (IMR)}

The number of infant deaths in the first year of life divided by the total number of live births (expressed per 1000). 


\section{INTER-PREGNANCY INTERVAL (SEE BIRTH INTERVAL)}

\section{INTRAUTERINE GROWTH RESTRICTION (IUGR) (FORMERLY REFERRED TO AS INTRAUTERINE GROWTH RETARDATION)}

A non-specific condition in which the fetus fails to reach its expected size at a given gestational age, where expected size may be suggested by (for example) serial ultrasound measures. In principle, growth restriction can occur to large fetuses as well as small. This term is commonly applied to babies in the lowest tenth centile of birth weight (or sometimes birth length), although not all small babies are growth restricted, and not all growth restricted babies are in the lowest centile of size. ${ }^{7}$ Thus, the preferred term for babies in the lowest centiles is "small for gestational age". (See SMALL FOR GESTATIONAL AGE)

\section{LAST MENSTRUAL PERIOD (LMP)}

First day of the last normal menses preceding pregnancy, often used as a benchmark to estimate gestational age and due date.

\section{LIVE BIRTH}

A baby who shows any signs of life after delivery (breathing, heart beat, pulsation of the umbilical cord, or definite movement of voluntary muscles), regardless of whether the umbilical cord has been cut or the placenta delivered. ${ }^{3}$ The ICD-10 definition does not specify an attained gestational age.

\section{MATERNAL MORTALITY}

Death of a woman from causes related to pregnancy or birth and occurring within six weeks of the termination of the pregnancy, ${ }^{3}$ or sometimes up to one year. ${ }^{8}$ The interpretation of "related to pregnancy" has been inconsistent, sometimes including women dying as a result of violence such as homicide or suicide. ${ }^{9}$

\section{NEONATAL MORTALITY}

Death of a liveborn infant within the first 28 days. (Early neonatal mortality is death within seven days.)

\section{Neonatal mortality rate}

Death within the first 28 days of life, divided by the total number of live births (expressed per 1000).

\section{OBSTETRIC DATES}

Gestational age is expressed in completed weeks rather than ordinal weeks. Thus a pregnancy in its 40 th week (say, at 39 weeks and 5 days) would be in obstetric week 39 .

\section{PARITY}

Number of births for a given woman, counting a multiple birth pregnancy as one. In some demographic studies, stillbirths do not count toward parity. (See GRAVIDITY)

\section{Nulliparous}

No previous.

Multiparous

One or more previous.

\section{PARTURITION}

Pertaining to childbirth.

\section{PERINATAL PERIOD}

"Perinatal" is a term with widely varying definitions across countries, due in part to legal variations in the time period that defines stillbirth. The ICD-10 defines "perinatal" as the time period starting at 22 completed weeks (154 days) gestation and lasting through seven days after birth.

\section{PERINATAL MORTALITY}

Fetal deaths beginning at 22 completed weeks (154 days) plus deaths of live births within the first seven days after birth. ${ }^{13}$ Live births eligible to be considered as perinatal deaths must be at least $500 \mathrm{~g}$, or 22 completed weeks of gestation, or $25 \mathrm{~cm}$ in body length to be included in many national perinatal statistics. For international perinatal mortality statistics, live births must have been either $1000 \mathrm{~g}$ or 28 completed weeks gestation or $35 \mathrm{~cm}$ in body length. ${ }^{10}{ }^{11}$

\section{PLACENTA}

An organ produced by the conceptus and bound to the mother's uterine lining, providing hormones and transporting essential nutrition and oxygen to the fetus through the umbilical cord.

\section{Abruptio placentae}

Detachment or separation of the placenta at any time prior to delivery. This can be a life threatening condition for both mother and fetus.

\section{Placenta previa}

The condition in which the placenta has grown over the internal cervical opening, presenting a danger of heavy bleeding at labour.

\section{PONDERAL INDEX}

A measure of infant fatness or leanness, defined as birth weight (in grams) multiplied by 100, and divided by the cube of crown-heel length (in centimetres). ${ }^{12}$

\section{POST-NEONATAL MORTALITY}

Death to a live birth after 28 days but within the first year of life. Neonatal plus post-neonatal mortality equals infant mortality.

\section{Post-neonatal mortality rate}

The number of deaths after 28 days but within the first year divided by the total number of live births. Neonatal plus postneonatal mortality rates equals the infant mortality rate (expressed per 1000).

\section{PRE-ECLAMPSIA}

A specific syndrome of pregnancy, defined by oedema, protein in urine, and hypertension in the mother. Diagnostic criteria can vary, leading to difficulties in comparisons across populations. Condition can progress to seizures (eclampsia), a rare but potentially disastrous condition curable only by delivery of the fetus.

\section{PRETERM DELIVERY}

Delivery before 37 completed weeks of gestation (less than 259 days).

\section{Premature (or prelabour) rupture of fetal membranes (PROM)}

Rupture before onset of labour.

\section{Preterm premature (or prelabour) rupture of fetal} membranes (PPROM)

Rupture before onset of labour and leading to a preterm delivery.

\section{Premature}

Until 1961, the World Health Organisation defined "prematurity" as birth weight less than 2500 grams. However, many infants born before 37 weeks weigh more than 
2500 grams, and many babies less than 2500 grams are not born early. Misuse of LBW to mean "premature" has lingered, and for this reason most perinatal epidemiologists avoid confusion by using "preterm" when discussing early birth.

\section{SEX RATIO}

Ratio of boys to girls at birth, restricted to singleton births and usually live births. Sex ratio is typically greater than one, reflecting an excess of boys (for example, 1.046 in the USA, 2001). ${ }^{13}$

\section{SMALL FOR GESTATIONAL AGE (SGA)}

Typically defined as the smallest $10 \%$ of birth weights at any given gestational age, sometimes adjusted for infant sex, ethnicity, maternal parity, and other factors. A condition associated with increased mortality and morbidity.

\section{SUDDEN INFANT DEATH SYNDROME (SIDS)}

The sudden and unexpected death of an infant in the first year and usually beyond the immediate perinatal period, unexplained by any known causes. ${ }^{14}$

\section{TERATOGEN}

An external substance, physical agent, or physical condition that is able to disrupt embryonic or fetal development, leading to birth defects.

\section{TERM PREGNANCY}

Pregnancy with delivery from the 37 th to the 42 nd obstetric week (259 to 293 days).

\section{Post-term delivery}

Delivery at 42 weeks or more completed weeks of gestation (294 days or more)..$^{15} 16$

\section{TRIMESTER}

Three roughly equal intervals of pregnancy based on obstetric dates. The first trimester begins on the first day of the last menstrual period (day 0 ) and goes through obstetric week 13 (97 days). The second trimester begins at 14 weeks (98 days), to the end of week 27 (195 days). The third trimester starts at 28 weeks (196 days) and ends with delivery. ${ }^{17}$

\section{TWINS, DIZYGOUS ('“FRATERNAL")}

Twins resulting from separate ova.

\section{TWINS, MONOZYGOUS ('IDENTICAL")}

Two or more infants in a pregnancy from a single fertilised ovum.

\section{WEINBERG'S FORMULA}

Inference of the rates of monozygotic and dizygotic twins in a population in the absence of clinical data, assuming that the number of unlike sex dizygotic twins equals the number of same sex dizygotic twins. ${ }^{18} 19$

\section{ACKNOWLEDGEMENTS}

The authors acknowledge the helpful comments provided on previous versions of this glossary, by: Dawn Misra, David Savitz, Olga Basso, Cande Ananth, and Mark Klebanoff. This work was supported by the Intramural Research Program at the National Institute of Environmental Health Sciences, NIH.

\section{CONTRIBUTORS}

Both authors have contributed equally to the manuscript.

\section{Authors' affiliations}

R H N Nguyen, A J Wilcox, Epidemiology Branch, National Institutes of Environmental Health Sciences, Research Triangle Park, North Carolina, USA

Funding: none.

Conflicts of interest: none declared.

\section{REFERENCES}

1 Apgar V. The newborn (Apgar) scoring system. Reflections and advice. Pediatr Clin North Am 1966:13:645-50.

2 Adams $M$, Andersen A-MN, Andersen $P$, et al. Sostrup statement on low birthweight. Intl J Epidemiol 2003;32:884-5.

3 World Health Organisation. ICD-10: International statistical classification of diseases and health related problems. Geneva: WHO, 1992.

4 Kowaleski J. State definitions and reporting requirements for live births, fetal deaths, and induced terminations of pregnancy (1997 revision). Hyattsville, MD: National Center for Health Statistics, 1997.

5 Gourbin C, Masuy-Stroobant G. Registration of vital data: are live births and stillbirths comparable all over Europe? Bull World Health Organ 1995; 73:449-60

6 Blondel B, Morin I, Platt R, et al. Algorithms for combining menstrual and ultrasound estimates of gestational age: consequences for rates of preterm and postterm birth. Br J Obstet Gynaecol 2002; 109:718-20.

7 Wilcox A. Intrauterine growth retardation: beyond birthweight criteria. Early Hum Dev 1983;8:189-93.

8 Chang J, Elam-Evans L, Berg C, et al. Pregnancy-related mortality surveillance-United States, 1991-1999. MMWR Surveill Summ 2003; 52:1-8

9 Dannenberg A, Carter D, Lawson $\mathrm{H}$, et al. Homicide and other injuries as causes of maternal death in New York City, 1987 through 1991. Am J Obstet Gynecol 1995; 172:1557-64

10 Macfarlane A, Mugford M. Birth counts: statistics of pregnancy and childbirth, Vol 1. London: The Stationery Office, 2000.

11 World Health Organisation. ICD-9: International statistical classification of diseases and health related problems. Geneva: WHO, 1980.

12 Chard T, Soc A, Costeloe K. The relationship of ponderal index and other measurements to birthweight in preterm neonates. J Perinat 1997:15:111-14.

13 Martin J, Hamilton B, Ventura S, et al. Births: final data for 2001. Natl Vital Stat Rep 2002;51:1-102.

14 Beckwith J. Defining sudden infant death syndrome. Arch Pediatr Adolesc Med 2003;157:286-90.

15 American College of Obstetrics and Gynecology. Diagnosis and management of post-term pregnancy. ACOG technical bulletin no 130. Washington, DC: American College of Obstetrics and Gynecology, 1989.

16 Hauth J, Goodman M, Gilstrap Lr, et al. Post-term pregnancy. Obstet Gynecol 1980;56:467.

17 American College of Obstetrics and Gynecology. Coding for medical and surgical termination of pregnancy/stillbirths. Washington, DC: American College of Obstetrics and Gynecology, 2004.

18 Lichtenstein P, Otterblad Olausson P, Bengt Kallen A. Twin births to mothers who are twins: a registry based study. BMJ 1996;312:879-81.

19 Weinberg W. Beitrdge zur physiologie und pathologie der mehrlingsgeburten bei menschen. Pfluegers Arch Ges Physiol $1901 ; 88: 346-430$ 